\title{
Voluntary Stopping of Eating and Drinking (VSED), Physician-Assisted Suicide (PAS), or Neither in the Last Stage of Life? PAS: $\mathrm{No}_{\text {; }}$ VSED: It Depends
}

\author{
Lynn A. Jansen, RN, PbD \\ Center for Ethics in Health Care, Portland Oregon \\ Ann Fam Med 2015;13:410-411. doi: 10.1370/afm.1849.
}

$\mathrm{T}$ The question is clear and straightforward: "Voluntary stopping of eating and drinking (VSED), physician-assisted suicide (PAS), or neither in the last stage of life?" An adequate answer to the question is neither clear nor straightforward. My position is that if one has reservations about PAS, as I do, then one ought to have some reservations about VSED as well.

The ethical permissibility of PAS continues to be an issue of ongoing ethical dispute. This much is obvious. What is much less obvious is the idea that the ethical permissibility of PAS and VSED are linked. The ethical permissibility of the latter depends in part on the ethical permissibility of the former.

Advocates for PAS often welcome VSED as another treatment option for addressing suffering at the end of life. As Bolt et al point out in this issue of Annals of Family Medicine, VSED provides patients "with a prolonged and reversible dying phase instead of the abrupt death in PAS, giving opportunity for reflection, family interaction, and mourning." For this reason, and for others, some terminally ill patients may prefer VSED over PAS, even when the latter option is legally available. With respect to those who oppose PAS, the issue of the ethical permissibility of VSED is considerably more complicated. To be sure, there are obvious differences between PAS and VSED and some of these reasons offered against PAS do not apply to VSED. Yet it is sometimes claimed that VSED "avoids moral

Conflicts of interest: author reports none.

\section{CORRESPONDING AUTHOR}

Lynn A. Jansen, RN, PhD

Center for Ethics in Health Care

3181 S.W. Sam Jackson Park Rd

Mailcode: UHN-86

Portland, Oregon 97239-3098

jansen@ohsu.edu controversy altogether"1 or that it represents "a simple solution" ${ }^{\prime 2}$ that can be accepted by both proponents and critics of PAS.

These claims are misleading. To see why they are misleading, it is necessary to distinguish the activity of VSED with the intention to end one's life from VSED understood as a clinical practice or treatment option. If a terminally ill patient, or any patient with decision making capacity, whether at the end of life or not, elects to forgo food and drink, then health care providers are morally obligated not to force them to receive medically delivered food and fluids.

Since the general right to refuse medical treatment is well established and widely acknowledged, it is tempting to view VSED as a simple implication of this general right. Viewed in these terms, VSED avoids moral controversy. Yet VSED is not simply an activity undertaken by patients to which health care providers then respond. In the literature on VSED it is commonly presented as a clinical practice or treatment option. Physicians, it is often said, should educate patients about this treatment option, recommend it as a response to end of life suffering, and provide support and system management throughout the process, including palliative sedation. Cumulatively, these steps go beyond respecting the rights of patients to refuse medical treatment and constitute significant physician involvement in, and complicity with, patients' decisions to forgo food and fluids as a means to address their suffering at the end of life. ${ }^{3}$

Once VSED is understood as a clinical practice, and not simply as an activity undertaken by a patient, its potential for controversy becomes clear. VSED is currently not part of standard of care in the United States, and in many other countries. Whether it should become part of standard of care is in part an ethical question. Some may fear that if VSED were to become a professionally accepted standard treat- 
ment option for suffering at the end of life, then it would be undertaken in inappropriate circumstances. Importantly, if VSED is not part of standard of care, then physicians do not have an obligation to inform or educate their patients about it, contrary to the claims of many who recommend this practice.

There are different cases to consider, of course. A patient who refuses food and fluids may resemble a patient who refuses artificial nutrition and hydration, judging that the burdens outweigh the benefits and that continued nutrition and hydration would be extraordinary and disproportionate treatment. Such a decision is not patient suicide. In contrast, patients who engage in VSED as a response to existential suffering or a sense of powerlessness or social isolation can be accurately described as killing themselves as a means to end suffering. Admittedly, the distinction between these different cases is not always sharp, and judgment is needed to make the relevant distinction, but its existence explains why PAS and VSED are linked. A number of the ethical objections to PAS apply to VSED, at least when it is recommended as an alternative route to the same end.
Advocates for PAS often present VSED as an alternative treatment option for end of life suffering that avoids moral controversy. But, in reality, VSED raises challenging moral questions about the permissibility of physician collaboration in patient decisions to end their lives as a means to ending their suffering.

To read or post commentaries in response to this article, see it online at http://www.annfammed.org/content/13/5/410.

Submitted July 26, 2015; submitted, revised, July 26, 2015; accepted July 26, 2015.

\section{References}

1. Bernat JL, Gert B, Mogielnicki RP. Patient refusal of hydration and nutrition: an alternative to physician-assisted suicide or voluntary active euthanasia. Arch Int Med. 1993;153(24): 2723-2731.

2. Savulescu J. A simple solution to the puzzles of end of life? Voluntary palliated starvation. J Med Ethics. 2014;40(2):110-113.

3. Jansen LA. No safe harbor: the principle of complicity and the practice of voluntary stopping of eating and drinking. J Med Phil. 2004;29(1): 61-74.1791.

\section{CORRECTION}

Ann Fam Med 2015;13:411. doi: 10.1370/afm.1791.

Ryan AM, Shortell SM, Ramsay PP, Casalino LP. Salary and quality compensation for physician practices participating in accountable care organizations. Ann Fam Med. 2015;13(4):321-324.

In Figure 2 of this paper, it should have reflected that primary care physicians in ACO practices on average received $49.0 \%$ of their compensation from salary, $46.1 \%$ from productivity, 3.4\% from quality, and $1.5 \%$ from other factors, but the figure was incorrect. The correct Figure 2 appears here and has been corrected in the online version of the paper. The online version therefore differs from the print journal. The author regrets the error.
Figure 2. Primary care physician compensation across financial risk and ACO participation.

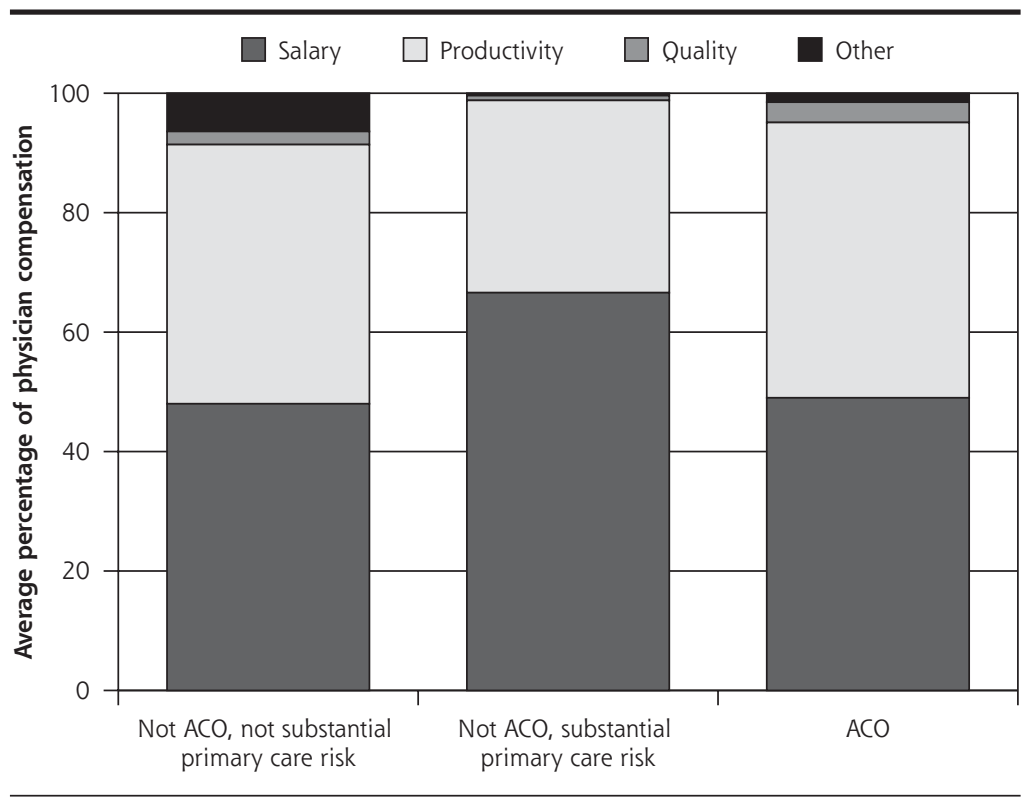

ACO = accountable care organization

Note: Substantial risk denotes that a practice bears at least some financial risk for primary care costs for all of its health maintenance organization or point-of-service patients. 